\title{
Study on Zhuhai's Strategic Positioning and Strategic Focus in Participating in the Construction of "The Belt and Road" Initiative
}

\author{
Liqin HU \\ Macau University of Science and Technology \\ Zhuhai City Polytechnic
}

\begin{abstract}
The Belt and Road" ("Silk Road Economic Belt" and "21st Century Maritime Silk Road") is a comprehensive opening-up strategy in the new era and also a national vision and action of the country.[1] Zhuhai is one of the earliest special economic zones established in China. It is the window for China's opening to the outside world and the pioneer for deepening reform. Therefore, the city should actively participate in the construction of "The Belt and Road" initiative. This paper analyzes the necessity of Zhuhai's participation in the construction of "The Belt and Road" initiative from micro, meso and macro levels, clearly defines the strategic positioning and strategic orientation of Zhuhai's participation in the construction of "The Belt and Road" initiative, and proposes the strategic focus of Zhuhai's participation in the construction of "The Belt and Road" initiative from five aspects.
\end{abstract}

Keywords-Zhuhai; "The Belt and Road"; Strategic positioning; Strategic focus

\section{NECESSITY OF ZHUHAI'S PARTICIPATION IN THE}

CONSTRUCTION OF "THE BELT AND ROAD" INITIATIVE

Since the development strategy of "The Belt and Road" was put forward in 2013, it has been upgraded to the all-round opening strategy of the party and the country in the new era. After a solid advancement in recent years, it is found that "The Belt and Road" is not only a national strategy of China, but also a vision and action of win-win and multi-win for the rest of the world to get on the fast track of China's economic development and share the fruits of China's peaceful development, so as to win an historic opportunity for its own economic and social development.

In the process of the party and state leaders proposing "The Belt and Road" strategic concept and rising to a national strategy, especially since the release of the Action and Vision, more than 30 provinces, autonomous regions and municipalities across the country have taken actions to strengthen research and action on the participation in the construction of "The Belt and Road". In the northwest: Shaanxi, Gansu, Qinghai, Ningxia and Xinjiang respond independently and cooperate with each other to promote the local economic and social development to a new level through the construction of the "Silk Road Economic Belt". On the southeast coast: Coastal provinces including Guangdong, Guangxi, Fujian, Hainan and Zhejiang are all in action, laying out the $21 \mathrm{st}$ century "Maritime Silk Road" strategy. With the continuous advancement of "The Belt and Road" strategy, the three northeast provinces and the vast central and western regions have also joined, showing a very active situation.

In order to seize the opportunity of the national "The Belt and Road" and the Guangdong Province's vigorous building of the "21st Century Maritime Silk Road", Zhuhai attaches great importance to this rare historic opportunity from top to bottom, from government agencies to civil organizations and enterprises, and actively participates in the construction of "The Belt and Road". For example: In February 2015, Zhuhai and Gwadar of Pakistan signed a memorandum to strengthen friendly exchanges and cooperation. Zhuhai Port Group will strengthen communication with Gwadar Port and discuss exchanges and cooperation in port construction. In December 2015, Zhuhai wrote "The Belt and Road" strategy in the Proposal of Zhuhai Municipal Committee of the Communist Party of China on Formulating the Thirteenth Five-Year Plan for National Economic and Social Development. Etc.

From the above three aspects, we can see: "The Belt and Road" is not only a "vision and action" initiative, but also a national strategic action from the beginning, which is a strategic choice for the continued rise of the Chinese nation. Zhuhai is named after the sea and thrives because of the sea. Its development is also closely related to the sea. Due to its unique advantages adjacent to Hong Kong and Macao, Zhuhai has become an important participant and beneficiary on the trade route of the ancient maritime silk road. Today's Zhuhai, in accordance with General Secretary Xi Jinping's goals and requirements for Zhuhai's construction, fully implements the "Blue Zhuhai, Science Rise" strategy. In the process of economic transformation and upgrading, coinciding with the introduction of the national "The Belt and Road" strategy, under the call and drive of Zhuhai Municipal Party Committee and Municipal Government to actively participate in "The Belt and Road" strategy, it should follow this trend to strengthen research, seize this rare historic opportunity, and adjust Zhuhai's economic, industrial and cultural development strategies and countermeasures, and win opportunities for the sustainable development and prosperity of Zhuhai's industry and the building of harmonious and happy Zhuhai. Its theoretical significance and practical value are very obvious. 


\section{StRATEGIC POSITIONING OF ZHUhai's PARTICIPATION} IN THE CONSTRUCTION OF "THE BELT AND ROAD" INITIATIVE

In 2013, when Chairman Xi Jinping proposed the idea of jointly building the "Silk Road Economic Belt", he put forward a step-by-step construction idea of "from point to area, from line to piece, and gradually forming regional cooperation", and put forward the "Five Links" initiative of strengthening policy communication, road connectivity, smooth trade, currency circulation and mutual understanding between people. This "Five Links" initiative is not only devoted to economic development, but also to the stability of international relations. It is an important basis for us to determine the strategic positioning and strategic orientation of participating in the construction of "The Belt and Road".

\section{A. Strategic Positioning}

According to the current international situation and the national development strategy, the initiative and arrangement of the Vision and Action, and the state's actual promotion of "The Belt and Road", strengthening the construction of the "Belt" ("Silk Road Economic Belt") and implementing the westward development strategy are the focus of "The Belt and Road" strategy, while the "21st Century Maritime Silk Road" is an equally important strategy to strive for the same goal, because the tasks of the 21 st century "Maritime Silk Road" are to expand the marine transportation route of "Atlantic Ocean Baltic Sea - Mediterranean Sea - Red Sea - Indian Ocean South China Sea - Pacific Ocean)"; "Caspian Sea - Black Sea Mediterranean Sea - Red Sea - Indian Ocean - South China Sea - Pacific Ocean"; "Atlantic Ocean - Indian Ocean -Pacific Ocean", expand trade contacts, port opening and cultural exchanges along the route, and finally promote economic, social and cultural development of the regions along the route through smooth trade channels and cultural exchanges. As the birthplace of the "Maritime Silk Road" and the spearhead of China's economy and foreign trade since the reform and opening up, Guangdong must actively explore and accumulate experience for the construction of the country's 21st century "Maritime Silk Road" and "fight the way out".

As the economic and cultural city of Guangdong Province, Zhuhai is the first region in China's modern history to fully contact Western culture and society and set the fashion. It is the bridgehead of the maritime silk road in history and the hub of economic and cultural exchange between China and the West. According to this, the strategic positioning of Zhuhai in the construction of "The Belt and Road" can be: Taking the "Belt" and "Road" into consideration, giving priority to participating in the "21st Century Maritime Silk Road", focusing on the development of the Southeast Asian market, taking the "Five Links" initiative as the core, and taking the lead in building Zhuhai into an important base for the modernization of commodity production, a bridgehead for foreign trade of goods, a strategic route for the import and export of goods and a transportation hub of the "21st Century Maritime Silk Road". In the "China to Southeast Asia, South Asia, and Indian Ocean" route planned by the national initiative Vision and Action, becoming the commodity production and trade core area and important transit station of "the key direction of the $21 \mathrm{st}$ Century Maritime Silk Road is from the Chinese coastal port to the Indian Ocean via the South China Sea and extending to Europe", "from the Chinese coastal port to the South Pacific Ocean via the South China Sea".

\section{B. Strategic Orientation}

In order to seize the opportunity of the national "The Belt and Road" and the Guangdong Province's vigorous building of the "21st Century Maritime Silk Road", Zhuhai has focused on strengthening economic and trade cooperation, trade and investment with ASEAN and South Asian countries. Next, Zhuhai can participate in the construction of "The Belt and Road" by means of government guidance, enterprise as the main body, industry association coordination, and management department and education organization cooperation on the existing basis[2], timely adjust the social economy, industry and cultural development strategy and countermeasures, use the going south strategy, take expanding and occupying the ASEAN market as a breakthrough, and set out in east, south and west: The east route faces the Americas, focusing on developing emerging markets in South America; The west route faces a wide range of emerging markets in Europe, South Asia, Central Asia, the Middle East and Eastern Europe, focusing on occupying Africa's virgin markets; The south route faces mainly Australia and New Zealand. Among the three, the central and western routes are the main routes, especially the geographically adjacent Southeast Asian countries and the vast Africa, which are the key development targets of Zhuhai. As long as the strategy is clear and the method is right, it can effectively implement the "encourage enterprises to 'go out'", "actively participate in the construction of 'The Belt and Road' and vigorously expand emerging markets in ASEAN, the Middle East and Latin America" proposed in the Work Report of Zhuhai Municipal Government, better realize the economic transformation and upgrading of Zhuhai, and win another important historic opportunity for the construction of Zhuhai.

\section{STRATEGIC FOCUS OF ZHUHAI'S PARTICIPATION IN THE CONSTRUCTION OF "THE BELT AND ROAD" INITIATIVE}

(1) Focus on making new breakthroughs in the development concept. The introduction of "The Belt and Road" strategy has given Zhuhai a new historical mission, broadened the open vision of Zhuhai, and further expanded the new space for the future development of Zhuhai. No matter "The Belt and Road" or The "Belt" or the "Road", it is a systematic project, and all parties need to actively participate in and promote it together. Based on the actual situation of Zhuhai, we should further emancipate our minds, strengthen our sense of opportunity, and thoroughly study and analyze the major benefits and favorable conditions brought about by the "21st Century Maritime Silk Road" for Zhuhai. We should think in all directions, comprehensively plan and enhance the predictability and timeliness of work; We should strengthen the awareness of cooperation, strengthen cooperation and interaction with provinces and cities along the "21st Century Maritime Silk Road", increase exchanges and cooperation with relevant countries, discuss development plans, form synergy for development, and achieve mutual benefits and win-win results. Strengthen open awareness, take the initiative to comply with the strategy of developing and opening up to the 
south of the state and province, and create an environment for development and integrate production factors with an open and inclusive mind, accept foreign investment with boundless tolerance, realize industrial transfer, and expand market space. At the same time, we should strengthen the awareness of innovation, adhere to promote the construction of the "21st Century Maritime Silk Road" with new concepts, new ideas and new perspectives, focus on deepening institutional reform in key areas and key links, strengthen policy system innovation, make full use of existing policies, and formulate new policies based on new economic development, and strive to maximize policy performance.

(2) Focus on making new breakthroughs in industrial development. In 2015, Zhuhai's economy was running well, the economic growth rate was stable, the industrial structure optimization and transformation and upgrading made new progress, and the economic quality and efficiency were steadily improved. The ratio of the three industries was 2.3:49.7:48.0. The structure is reasonable. We will continue to play the decisive role of the market in resource allocation on the basis of existing successful experience. In order to achieve new breakthroughs in industrial development, we should urge all parties to work together, conscientiously study the resource endowments, industrial characteristics and development trends of the countries along the "21st Century Maritime Silk Road", actively seek for industrial fitting points and resonance points between Zhuhai and neighboring countries, and cooperate with the surrounding cities to hold Zhuhai special product promotion meetings regularly by contacting the Chinese Chamber of Commerce of the countries along "The Belt and Road". Promote the superior products of Zhuhai to the international market through the exhibitions and overseas ecommerce platforms. Facilitate qualified enterprises to invest and set up factories in countries and regions along "The Belt and Road", and make Zhuhai headquarters the R\&D and backend service center by taking advantage of their abundant resources and low labor cost. This will not only solve the employment problems in these countries, increase the tax revenue for the local government, but also reduce the production cost and increase the profit margin of the enterprises, and achieve win-win or multi-win objectives.

(3) Focus on making new breakthroughs in infrastructure construction. Zhuhai's infrastructure construction as a whole can meet the needs of social production development. With the development of the economy and society, in the future, while increasing local infrastructure investment, it is necessary to make good use of national and provincial policies and strive for various funds including AIIB and Guangdong Silk Road Fund, further increase the infrastructure construction in the region, including the completion of the three-dimensional integrated transportation hub led by Hong Kong-Zhuhai-Macao Bridge, and the building of the "one bridge and two ports" traffic pattern led by Hong Kong-Zhuhai-Macao Bridge, support the city to "develop in four directions", and enter the one-hour time and space circle of other cities in the Pearl River Delta; Improve the traffic efficiency of the eastern main city and improve the road network framework; Accelerate the editing and revision of the overall planning of Zhuhai Airport and the demonstration of the second runway, promote the opening of the airport international port, and strive to build an important freight airport in Guangdong Province. Speed up the construction of general airports and develop low-altitude air routes. Actively participate in the construction of the Pearl River-Xijiang Economic Belt, comprehensively promote the regional cooperation of Zhuhai, Zhongshan, Jiangmen and Yangjiang, and play the linkage effect of Hengqin Free Trade Zone, Western Ecological New City, Zhuhai Cuiheng New District and Jiangmen Daguang Bay Economic Zone, and form a more modern three-dimensional transportation network as soon as possible

(4) Focus on making new breakthroughs in cultural exchanges[3].The urban culture of Zhuhai has the characteristics of openness, and the foreign exchanges and exchanges continue to advance. Zhuhai should give full play to this unique advantage and fully mobilize the enthusiasm and strength of overseas Chinese to pay attention to Zhuhai and support Zhuhai. By adopting the method of active coordination and cooperation between the government and the people, close the official to official and folk to folk reciprocal exchanges between Zhuhai and countries along "The Belt and Road", and actively realize the strategy of cultural going out. For example, on the afternoon of October 21, 2016, at the 25th Fenghuo Wenchuang Forum and the 9th Zhuhai Cultural Industry Salon held in Yang's Great Ancestral Hall, Beishan Village, Zhuhai, the research results of Zhuhai's '13th Five-Year' Development Plan of Cultural and Creative Industries' and White Paper on Cultural and Creative Industries of Zhuhai in 2015 were officially released. The preparation of the Planning closely follows the development strategies of the state and Guangdong Province, such as "The Belt and Road" and other strategies, and fully reflects the new normal of cultural and creative industry development under the background of the times, like the introduction of international cultural elements such as the global Portuguese culture, Hong Kong and Macao culture and the Maritime Silk Road. Relevant departments should organize social science experts and scholars, folk think tanks, deputies to the National People's Congress, and CPPCC members to strengthen research on related issues of "The Belt and Road".

(5) Focus on making new breakthroughs in improving the level of opening up. Zhuhai has made important contributions to the country's development and modernization in both modern and contemporary history and after the reform and opening up. Therefore, in "The Belt and Road" strategy proposed by the country today, Zhuhai should not be absent, but take active actions to make a difference. This is the inevitable result of historical development and is decided by the development law of Zhuhai's market economy and the industrial characteristics today. At the government level, we should establish a good relationship with the countries along "The Belt and Road". We can consider forming a pair of friendly cities in each country. Through this friendship window, we can publicize and promote ourselves in all directions and build a comprehensive cooperation platform[4];Taking advantage of the hometown of overseas Chinese and the active situation of non-governmental exchanges in Zhuhai, we should actively develop Zhuhai's public diplomacy and help Zhuhai to connect with the construction of "The Belt and Road". Fully consider its own location advantages and economic advantages, 
cooperate with the Implementation Plan of Guangdong Province, highlight the "21st Century Maritime Silk Road Construction", highlight the cooperation between Guangdong, Hong Kong and Macao, and highlight economic and trade cooperation; While strengthening cooperation, it should deepen the reform of customs clearance at ports, promote the integration of electronic port system construction and regional customs clearance in the province, and vigorously develop service trade, actively cultivate foreign trade brands and overseas marketing networks in the cross-border e-commerce pilot cities to promote the construction of municipal-level cross-border trade e-commerce parks; Support Zhuhai's products to be included in the procurement directory of international organizations, strengthen the docking and cooperation with the provincial free trade zone, and study and establish a comprehensive bonded port area to further enhance Zhuhai's level of opening up.

\section{CONCLUSION}

Zhuhai's participation in the construction of "The Belt and Road" is very necessary. On the basis of clearly defining the strategic positioning and strategic orientation of the participation in the construction of "The Belt and Road", it should achieve key breakthroughs on development concepts, industrial development, infrastructure construction, cultural exchanges and the level of opening up, and strive to better play the role of spearhead and main force in the implementation of national strategic decisions.

\section{ACKNOWLEDGMENT}

About the author: Liqin HU (1980-), female, from Wuhan, Hubei, a doctoral candidate student of International relations of Institute of Social and Cultural Studies, Macao University of Science and Technology enrolled in 2014, lecturer of Zhuhai City polytechnic. Major research direction: Chinese and foreign cultural exchanges.

Funds: The fourth batch (2014) project of the "12th FiveYear Plan" of Education and Scientific Research in Zhuhai "Study on the Application of Zhuhai's Historical and Cultural Resources in the Teaching of Ideological and Political Theory Course" (2014KTG15).

\section{REFERENCES}

[1] Weidong LIU. Scientific Understanding of the Belt and Road Initiative of China and Related Research Themes [J]. Progress in Geography. 2015(5)

[2] Guping ZHOU, Yue KAN. Talent Support and Education Path of "The Belt and Road" Strategy [J]. Educational Research. 2015(10)

[3] Xiaomin LI. Analysis of the Expansion of China's Cultural Industry under the Background of "The Belt and Road" [J]. Qiushi, 2016(7)

[4] Yiwei WANG. "The Belt and Road": Opportunities and Challenges [M]. Beijing: People's Publishing House, 2015. 